\title{
Stable Dispersion of lodide-Capped PbSe Quantum Dots for High- Performance Low-Temperature Processed Electronics and Optoelectronics
}

\author{
Vladimir Sayevich, ${ }^{\dagger}$ Nikolai Gaponik, ${ }^{\dagger}{ }^{\dagger}$ Matthias Plötner, ${ }^{\ddagger}$ Marta Kruszynska, ${ }^{\dagger}$ Thomas Gemming, ${ }^{\S}$
} Volodymyr M. Dzhagan," Shahab Akhavan, ${ }^{\perp}$ Dietrich R. T. Zahn," Hilmi Volkan Demir, ${ }^{\perp, \#}$ and Alexander Eychmüller ${ }^{\dagger}$

\begin{abstract}
${ }^{\dagger}$ Physical Chemistry and Center for Advancing Electronics Dresden, TU Dresden, Bergstr. 66b, 01062 Dresden, Germany
${ }^{\ddagger}$ Electrical and Computer Engineering, Institute of Semiconductors and Microsystems, Nöthnitzer Straße 64, 01187 Dresden, Germany

${ }^{\S}$ Institute for Complex Materials, IFW Dresden, Helmholtzstraße 20, 01069 Dresden, Germany

"Semiconductor Physics, Technische Universität Chemnitz, D-09107 Chemnitz, Germany

${ }^{\perp}$ Department of Physics, Department of Electrical and Electronics Engineering, UNAM-Institute of Materials Science and Nanotechnology, Bilkent University, TR-06800, Ankara, Turkey

"Luminous! Center of Excellence for Semiconductor Lighting and Displays, School of Electrical and Electronic Engineering, School of Physical and Mathematical Sciences, Nanyang Technological University, Nanyang Avenue, Singapore 639798, Singapore
\end{abstract}

\section{Supporting Information}

ABSTRACT: Here, we present a ligand exchange of long insulating molecules with short, robust, and environmentally friendly iodide ions via a mild flocculation of $\mathrm{PbSe}$ nanocrystals (NCs). This ligand exchange leads to the formation of stable colloidal solutions in various polar solvents and in a broad concentration range via electrostatic repulsion. The iodide capping ligands preserve the electronic structure and maintain the optical properties of the PbSe NCs, both in solution and in the form of solid films. The spin-coated $\mathrm{PbSe} \mathrm{NC}$ solids exhibit good transport characteristics with electron mobilities in the linear and saturation regimes reaching $(2.1 \pm 0.3) \mathrm{cm}^{2} /(\mathrm{V} \cdot \mathrm{s})$ and $(2.9 \pm 0.4)$ $\mathrm{cm}^{2} /(\mathrm{V} \cdot \mathrm{s})$, respectively. This opens up opportunities for the low-cost and low-temperature fabrication of NC thin films being attractive for applications in the fields of electronics and optoelectronics.

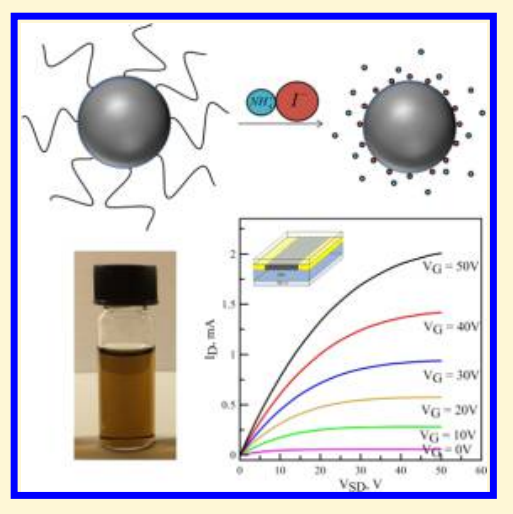

\section{INTRODUCTION}

Colloidal semiconductor nanocrystals (NCs) attract tremendous scientific and technological interest for their unique sizeand shape-tunable optical, electrical, and magnetic properties as well as an inclination to the formation of self-assembled nanocrystal solids. ${ }^{1}$ There is a distinguished interest in lead selenide (PbSe) NCs due to their narrow band gap $(0.26 \mathrm{eV}$ for the bulk material), small effective masses for both electrons and holes $\left(\sim 0.1 \mathrm{~m}_{0}\right)$, large exciton Bohr radius (46 $\left.\mathrm{nm}\right)$, high dielectric constant $(\varepsilon \sim 23)$, and 8 -fold degenerated $1 S$ quantum confined orbitals in the rock-salt crystal structure. ${ }^{2-7}$ All this together makes PbSe NCs very attractive for various electronic and optoelectronic applications, including field-effect transistors (FETs), ${ }^{7}$ thermoelectrics, ${ }^{8}$ photodetectors, ${ }^{9}$ and solar cells. ${ }^{10}$ However, the colloidal NCs prepared in high temperature boiling solvents, typically capped with long-tail organic ligands, cannot be directly implemented in electronic circuits due to the weak interparticle coupling.
To tackle the problem, several strategies of postsynthetic ligand exchange of the initial bulky and strongly insulating molecules with shorter ones can be applied. ${ }^{1}$ The Talapin and Kovalenko groups have successfully functionalized the surface of NCs with various new ligands via solution-phase ligand exchange, yielding all-inorganic PbX NC colloids $(X=S, T e)$. This method is exceptionally interesting as it enables the preservation of the colloidal dispersibility of the NCs and the formation of NC solids with short interparticle separation by using a single processing step and avoiding shrinkage and cracking of the thin films. Thus, PbTe NCs capped with molecular metal chalcogenide (MCC) ligands, such as $\mathrm{Sb}_{2} \mathrm{Te}_{3}$ MCC dissolved in hydrazine, ${ }^{11}$ and later $\mathrm{PbS}$ and $\mathrm{PbTe} \mathrm{NCs}$, stabilized with $\mathrm{SnS}_{4}{ }^{4-}, \mathrm{Sn}_{2} \mathrm{~S}_{6}{ }^{4-}, \mathrm{MoS}_{4}{ }^{2-}$, and $\mathrm{SnTe}_{4}{ }^{4-}$ and dispersed in environmentally benign solvents such as water and

Received: March 2, 2015

Revised: $\quad$ May 23, 2015

Published: May 27, 2015 
formamide (FA) ${ }^{12}$ were demonstrated. All MCCs are easily thermally decomposed to their parent metal chalcogenides which serve as an "electronic glue" and functional interparticle medium for NC-based solids leading to dramatically improved transport characteristics. ${ }^{13}$ Metal free ions such as $\mathrm{TeS}_{3}{ }^{2-}$ having a molecular structure and being intermediate between MCCs and polychalcogenides as well as $\mathrm{Te}^{2-}$ were used as ligands for producing stable colloidal FA solutions of $\mathrm{PbS}$ and PbTe NCs, respectively. ${ }^{14}$ The Murray group extended the work with metal-free ligands and managed to measure the Hall effect in nonsintered thiocyanate-capped PbTe thin films which showed a high mobility of $\sim 3 \mathrm{~cm}^{2} /(\mathrm{V} \cdot \mathrm{s})$ in films from $7.5 \mathrm{~nm}$ PbTe NCs. ${ }^{13}$ Recently, Dirin et al., ${ }^{16}$ Zhang et al., ${ }^{17}$ and Kim et al. ${ }^{18}$ expanded the chemical versatility of $\mathrm{PbS}$ and $\mathrm{PbTe}$ NCs by stabilizing them with halometallates-isocationic lead halide perovskites, $\mathrm{CH}_{3} \mathrm{NH}_{3} \mathrm{PbHal}_{3}$, metal halide complexes $\mathrm{PbHal}_{2}$ $\left(\mathrm{Hal}=\mathrm{I}, \mathrm{Br}\right.$ ), as well as the aliocationic $\mathrm{InI}_{3}, \mathrm{SbCl}_{3}$, and $\mathrm{NH}_{4} \mathrm{I}$. The methylammonium lead iodide and bromide reduced the density of the surface states, which lead to enhanced photoluminescence (PL) from the NCs after ligand exchange, reaching a quantum yield of $25 \%$. In nonpolar solvents, halide ligands have been employed as cosurfactants together with organic ligands for colloidally synthesized NCs. For example, $\mathrm{Cl}^{-}$ions for $\mathrm{PbS}$ and $\mathrm{PbSe}^{10,19}$ and $\mathrm{Br}^{-}$and $\mathrm{I}^{-}$for $\mathrm{PbSe}^{20}$ led to an increased air stability of the lead chalcogenide NCs, which otherwise are known to be highly susceptible to oxidation.

In addition to these results on the ligand exchange in the liquid phase as described above, numerous approaches were developed allowing for a solid-phase ligand exchange. This strategy involves first an assembling of the NCs into a solid and then treating the resulting film with a solution containing the new ligand. ${ }^{15}$ This method is of special importance when attempts to functionalize lead chalcogenide colloids with short ligands fail. Successful examples of solid-state exchange applied to lead chalcogenide films include simple amines 7,21 and alkaneditiols, $^{22,23}$ as well as tetrathiafulvalenetetracarboxylate, ${ }^{24}$ sulfide, ${ }^{25}$ selenide, ${ }^{26,27}$ and methoxide ${ }^{28}$ ions. Moreover, studies of an atomic-ligand passivation with metal-free halide ions $\left(\mathrm{Cl}^{-}\right.$, $\left.\mathrm{Br}^{-}, \mathrm{I}^{-}\right)$pursued by the Sargent group have convincingly demonstrated the efficiency of the solid-state ligand exchange approach for the replacement of organic ligands on $\mathrm{PbS} \mathrm{NCs}$ which are used as the active layer in solar cells with an efficiency of $6-8 \% .^{29,30}$

Despite this success, there is only limited information available on obtaining stable colloidal PbSe NC solutions, capped with either one of the aforementioned small inorganic ligands or with larger molecules, like pyridine, hydrazine, or 1,2ethanedithiol.

The success of a ligand exchange is defined by the individual NC properties, ligand nature, and conditions at which the surface modification of the NCs takes place. The shape and composition of lead chalcogenide NCs may be varied in a broad range, leading to changing their inherent anisotropy, crystal surface reactivity, and increasing structural difference between their facets. ${ }^{31-33}$ Nonstoichiometry of NCs with an excess of the undercoordinated centers, the different affinity to the surface of the upcoming and leaving ligands, their hardness and softness, as well as the solvation energy may change the thermodynamics and kinetics of the solution ligand exchange process. Moreover, possible mismatching of the lattice constants and coordination numbers between interacting NCs and ligands should be taken into account. The scarce information on getting all-inorganic dispersions of $\mathrm{PbSe} \mathrm{NCs}$ is likely related to any of the above-mentioned features which may limit the stabilization of PbSe NCs.

This has motivated us to look for reliable, short inorganic ligands which would not only stabilize colloidal particles of $\mathrm{PbSe}$ but can also efficiently passivate surface states. The success of this work will complement the list of stable processable solutions of all-inorganic capped lead chalcogenides.

Here, we present the successful ligand exchange of oleic acid (OA) molecules with tiny iodide ions via a mild flocculation of $\mathrm{PbSe}$ NCs allowing for the formation of stable colloidal solutions in various polar solvents and in a broad range of concentrations. The iodide ligands are substantially shorter than the OA and may form closely packed films with short interparticle separations which are detrimental for good electric conductance.

In this paper, we address the problems of air-stability and trap passivation being of importance for reasonable transport characteristics and practical applications. We utilized the advantages of postsynthetic atomic layer deposition (ALD) $)^{34}$ and solution treatment ${ }^{35}$ techniques to reduce the density of surface states and to tune the carrier concentration in the NC solids. ALD has been already successfully used to gently infill the voids of conductive $\mathrm{NC}$ films with $\mathrm{ZnO}$ or $\mathrm{Al}_{2} \mathrm{O}_{3}$ and to produce air stable nanocomposites for FETs and solar cells with enhanced performance. ${ }^{26,36,37}$ In turn, chalcogenide $\left(S^{2-}\right.$ and $\mathrm{Se}^{2-}$ ) and $\mathrm{PbCl}_{2}$ solution treatments were also implemented to tailor the stoichiometry and electronic properties of $\mathrm{PbSe}$ and $\mathrm{PbS}$ NCs. ${ }^{27}$ We successfully applied both techniques, leading to an electron mobility of $\sim 2 \mathrm{~cm}^{2} /(\mathrm{V} \cdot \mathrm{s})$ after $\mathrm{ALD}$ of $\mathrm{Al}_{2} \mathrm{O}_{3}$ and a hole mobility of $\sim 0.04 \mathrm{~cm}^{2} /(\mathrm{V} \cdot \mathrm{s})$ in the linear regime after solution treatment with $\mathrm{AlCl}_{3}$.

\section{EXPERIMENTAL SECTION}

Chemicals. Lead oxide(II) (PbO, 99.999\%, Aldrich), oleic acid (OA, 90\%, Aldrich), 2,6,10,15,19,23-hexamethyltetracosane or squalane (99\%, Aldrich), trioctylphosphine (TOP, 97\%, STREM), selenium powder (Se, 100 mesh, 99.99\%, Aldrich), ammonium iodide (99.999\%, Aldrich), ammonium bromide (99.999\%, Aldrich), ammonium chloride (99.999\%, Aldrich), trimethylaluminum, tetrakis(dimethylamido)hafnium, propylene carbonate (PC, anhydrous, 99.7\%, Aldrich), $\mathrm{N}$-methylformamide (MFA, 99\%, Aldrich), N,Ndimethylformamide (DMF, anhydrous, 99.8\%, Aldrich), formamide (FA, anhydrous, 99\%, Aldrich), tetrachloroethylene (TCE, anhydrous, $>99 \%$, Aldrich), hexane (anhydrous $>99 \%$, Alfa Aesar), acetone (anhydrous >99\%, Merck), methanol (anhydrous, >99\%, Aldrich), ethanol (anhydrous $>99 \%$, Merck), and $n$-butanol (99.8\%, Aldrich) were used as received. PC, MFA, and DMF were dried under a vacuum; hexane, acetone, methanol, and ethanol were degassed. All chemicals for ligand exchange were stored and handled inside the glovebox.

Lead Selenide Nanocrystal Synthesis. PbSe NCs with low polydispersity were synthesized using a modification of the method developed by Talapin et al.: $0.4768 \mathrm{~g}$ of $\mathrm{PbO}$ and $2.74 \mathrm{~mL}$ of oleic acid were dissolved in $15 \mathrm{~mL}$ of squalane. The mixture was heated to $116^{\circ} \mathrm{C}$ under a vacuum $\left(\sim 10^{-2} \mathrm{mbar}\right)$ for $2.5 \mathrm{~h}$ to form a yellow and clear solution of lead oleate. The color probably appears due to the formation of a complex with the solvent under these conditions. Then, the resulting solution was heated to the desired temperature and kept for $30 \mathrm{~min}$ before injection of $6.75 \mathrm{~mL}$ of $1 \mathrm{M}$ TOPSe (the injection temperature was varied from 150 to $220{ }^{\circ} \mathrm{C}$ to obtain different sizes of the NCs). To enlarge the NCs to sizes beyond $7 \mathrm{~nm}$, additional multiple injections of lead oleate and TOPSe were done at $T=140{ }^{\circ} \mathrm{C}$ for $30 \mathrm{~min}$ to $1.5 \mathrm{~h}$ using a syringe pump. The NCs were grown for 2 min followed by an abrupt cooling using icy water. In order to precipitate the NCs, $n$-butanol was added to the crude solution. The 


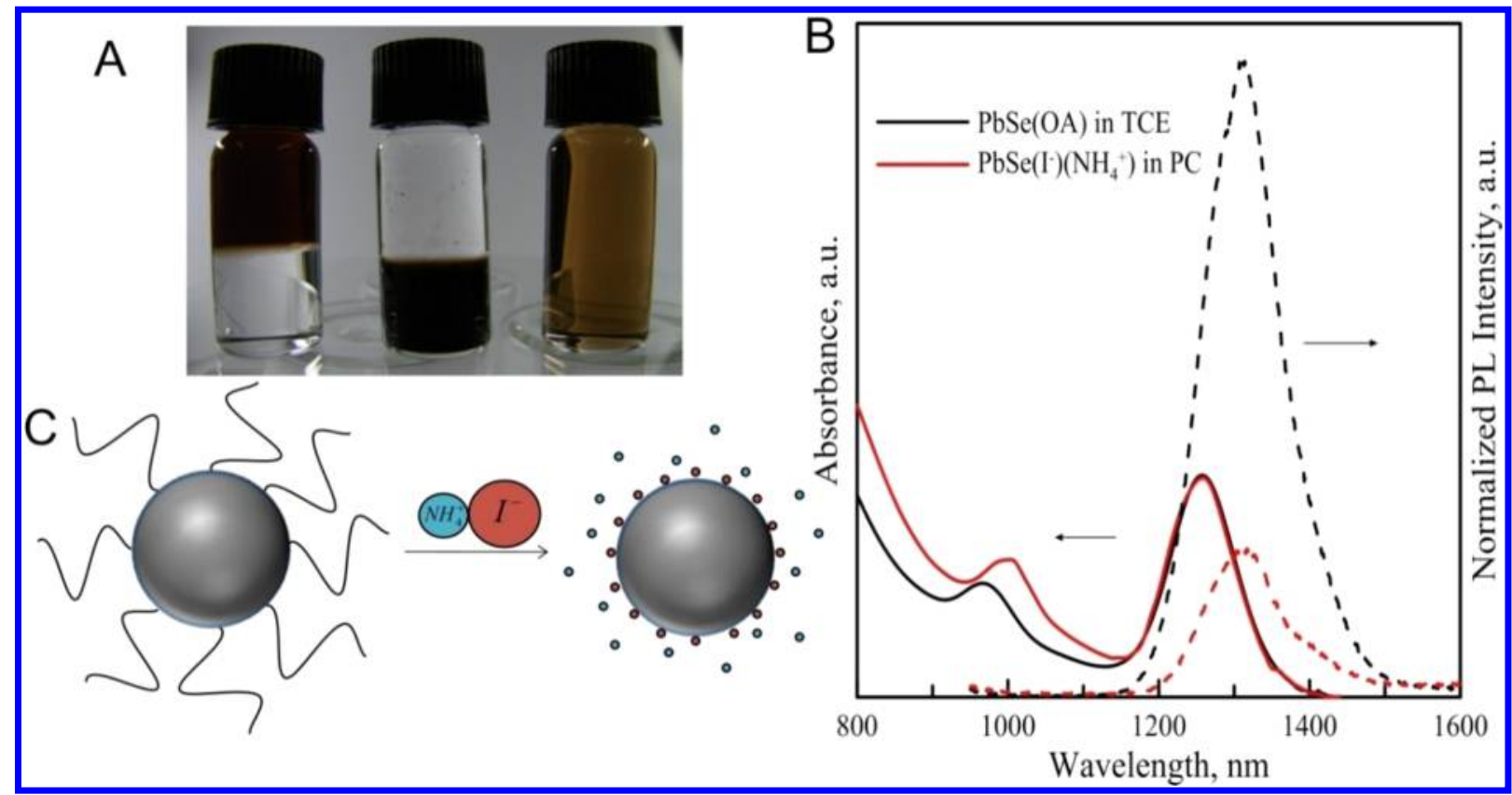

Figure 1. (A) Biphasic hexane and PC mixture containing PbSe NCs dispersed in the hexane phase before ligand exchange (left). NCs treated with $\mathrm{NH}_{4} \mathrm{I}$, washed, and redispersed in PC with hexane added to the top after ligand exchange (middle). A diluted solution of NCs in PC (right). (B) NIR absorption (solid line) and emission spectra (dashed line) of the same NCs capped with organic and $\mathrm{I}^{-}$ligands in TCE and PC, respectively, are compared, showing the well-resolved quantum confinement characteristics. (C) Schematics of the ligand exchange of OA molecules with ammonium iodide.

colloid was further centrifuged, and the precipitate was redispersed in pure hexane. This cleaning step was repeated twice with ethanol as the nonsolvent. Finally, the PbSe NCs capped with OA were redispersed in hexane and stored in a glovebox.

Solution-phase Ligand Exchange of Organic Ligands with Ammonium Halides. The ligand exchange was carried out in an oxygen-free atmosphere, which is crucial for the preparation of samples suitable for the fabrication of solid films with high electronic performance. A total of $300 \mu \mathrm{L}$ of $1 \mathrm{M}$ solution of $\mathrm{NH}_{4} \mathrm{I}$ in MFA was mixed with $2.7 \mathrm{~mL}$ of neat acetone and then added to the diluted solution of the PbSe particles in hexane $(6 \mathrm{~mL}, \sim 9 \mathrm{mg} / \mathrm{mL})$. After vigorous shaking, the fluffy-like aggregated NCs were centrifuged and separated from the supernatant. An excess of acetone was added to the precipitate to remove the remaining oleic acid and unreacted $\mathrm{NH}_{4} \mathrm{I}$. After centrifugation and drying, the powder was redispersed in $3 \mathrm{~mL}$ of MFA. The clear solution was then precipitated with a hexane/acetone mixture (1:2 in volume). The dried powder was easily redispersed in pure MFA, forming stable and concentrated solutions due to electrostatic repulsion in the polar solvent. Concentrations as high as $220 \mathrm{mg} / \mathrm{mL}$ were easily achieved. Instead of MFA, PC, DMF, or FA might also be used as solvents for the $\mathrm{PbSe}$ powder. For the ligand exchange with ammonium bromide $\left(\mathrm{NH}_{4} \mathrm{Br}\right)$ and ammonium chloride $\left(\mathrm{NH}_{4} \mathrm{Cl}\right)$, we used the $300 \mu \mathrm{L}$ of saturated solution of the salts in MFA, $1.5 \mathrm{~mL}$ of acetone, and $400 \mu \mathrm{L}$ of pure MFA as a nonsolvent mixture. The concentration of $\mathrm{PbSe}$ in hexane, used in the ligand exchange procedure, was $\sim 4 \mathrm{mg} / \mathrm{mL}$.

Structural and Optical Characterization. An absorption spectrum of the solutions and of the thin films were acquired using a Cary 5000 UV-vis-NIR spectrometer. The absorption spectra of the films were obtained by recording transmittance and total reflectance using an integrating sphere. Steady-state PL spectra were collected using a Fluorolog 3 spectrofluorometer (HORIBA JobinYvon) equipped with an InGaAs detector. The excitation wavelength was $850 \mathrm{~nm}$, provided by a $450 \mathrm{~W}$ xenon lamp and a monochromator. The spectral response of the detector was taken into account. Oleic acid and iodide-stabilized PbSe NCs were dispersed in TCE and PC (or MFA), respectively. Attenuated total reflectance Fourier transform infrared (ATR-FTIR) spectra were acquired in the transmission mode using a Thermo Scientific Nicolet iS5 FTIR spectrometer and averaging over 64 scans.

Transmission electron microscopy (TEM) of the samples was performed using an FEI Tecnai F30 microscope operated at $300 \mathrm{kV}$ and equipped with an energy dispersive X-ray spectrometer (EDXS) EDAX EDAMIII. Scanning electron microscopy (SEM) imaging was carried out on a Zeiss DSM 982 Gemini instrument operating at $8 \mathrm{kV}$. Powder X-ray diffraction patterns were collected with a Bruker AXS D2 PHASER diffraction system in the reflection mode. A nickel filter, $\mathrm{Cu} \mathrm{K} \alpha 1$ irradiation, and a LYNXEYE/SSD160 detector were used.

Thermogravimetric analysis (TGA) was conducted using a Mettler Toledo TGA/DSC1 Star System thermal analyzer with a heating rate of $6{ }^{\circ} \mathrm{C} / \mathrm{min}$ under nitrogen. Dynamic light scattering (DLS) and $\xi$ potential data were collected using a ZetasizerNano-ZS (Malvern Instruments, Inc.) The colloidal solutions were filled into a quartz cuvette, and a dip-cell setup with Pd electrodes was used to apply an electrical field to the solutions of the NCs. The concentration was optimized for each sample to achieve high count rates (>100 kcps) and good signal-to-noise ratios. The measurement of the $\xi$-potentials included three scans of 70 runs. The DLS data reported are averages of five measurements of 30 scans.

X-ray Photoemission Spectroscopy (XPS) investigations were performed with an ESCALAB 250Xi X-ray Photoelectron Spectrometer Microprobe (Thermo Scientific). Spectral resolution of $0.5 \mathrm{eV}$ was provided by a monochromized $\mathrm{Al} \mathrm{K}_{\alpha}(h \nu=1486.6 \mathrm{eV}) \mathrm{X}$-ray source. To prevent possible charging of the samples, a flooding of the sample with low kinetic energy electrons was used. Spectra deconvolution and quantification were performed by Avantage Data System (Thermo Scientific). For XPS study, the samples were prepared under an inert atmosphere by drop-casting a thin NC film on a precleaned $\mathrm{Si}$ substrate.

Field Effect Transistor Device Fabrication and Atomic Layer Deposition. Highly doped silicon substrates coated with a 100-nm(for ALD) and 200-nm- (for solution treatment) -thick thermally grown $\mathrm{SiO}_{2}$ gate oxide and prepatterned with $5 \mathrm{~nm} \mathrm{Ti} / 35 \mathrm{~nm} \mathrm{Au}$ source (drain) electrodes were used as substrates for field-effect transistor measurements. The ratios of channel length to channel width were 20 to $3000 \mu \mathrm{m}$ for solution-treated and 50 to $1000 \mu \mathrm{m}$ for ALD-treated samples, respectively. These substrates were shortly $(\sim 10$ 
min) cleaned by piranha $\left(\mathrm{H}_{2} \mathrm{SO}_{4}\right.$ conc. $\left./ 30 \% \quad \mathrm{H}_{2} \mathrm{O}_{2} \quad 2 / 3 \quad \mathrm{~V} / \mathrm{V}\right)$ treatment followed by multiply rinsing with milli- $\mathrm{Q}$ water before usage. In some cases, the dispersions of PbSe particles $(60-150 \mathrm{mg}$ / $\mathrm{mL}$ in $1 / 3 \mathrm{~V} / \mathrm{V}$ MFA/PC mixture) capped with iodide ions were additionally purified by centrifugation at $10 \times 10^{3} \mathrm{rmp}$ for $8 \mathrm{~min}$ before further processing. PbSe NC-based films ( $\sim 50 \mathrm{~nm}$ thickness) were deposited by spin-casting the dispersion onto the cleaned substrate at $500 \mathrm{rpm}$ for $5 \mathrm{~s}$ followed by $2000 \mathrm{rpm}$ for $40 \mathrm{~s}$ at elevated temperatures of $70-80{ }^{\circ} \mathrm{C}$ maintained by an infrared lamp placed above the substrate. Immediately after spin-coating, the films were placed in a vacuum antechamber to remove the rest of the solvent. The film fabrication steps were performed inside a glovebox. A similar film fabrication on quartz substrates was carried out for optical characterizations under air.

Low-temperature $\mathrm{ALD}$ with amorphous $\mathrm{Al}_{2} \mathrm{O}_{3}$ or $\mathrm{HfO}_{2}$ infilling was carried out using a Savannah ALD system, and $\mathrm{Al}\left(\mathrm{CH}_{3}\right)_{3}$ or $\mathrm{Hf}\left(\mathrm{NMe}_{2}\right)_{4}$ and $\mathrm{H}_{2} \mathrm{O}$ precursors as aluminum (hafnium) and oxygen sources, respectively. The operating pressure was 0.09 Torr. The mass flow was $20 \mathrm{sccm}$; the pulsed deposition and waiting times were $15 \mathrm{~ms}$ and $60 \mathrm{~s}$, respectively for $\mathrm{Al}_{2} \mathrm{O}_{3}$. In the case of $\mathrm{HfO}_{2}$, the pulsed (waiting) times were $0.15 \mathrm{~s}(60 \mathrm{~s})$ and $15 \mathrm{~ms}(60 \mathrm{~s})$ for $\mathrm{Hf}\left(\mathrm{NMe}_{2}\right)_{4}$ and $\mathrm{H}_{2} \mathrm{O}$, respectively.

The infilling temperature was chosen to be $87^{\circ} \mathrm{C}$, leading to a fast formation of $10 \mathrm{~nm} \mathrm{Al} \mathrm{O}_{3}$ and $\mathrm{HfO}_{2}$ films and to simultaneously protecting the quantum confinement structure of the PbSe NC solids. Solution treatment of the PbSe NC solids, capped with $\mathrm{I}^{-}$ions was performed by dipping the $\mathrm{NC}$ films $(\sim 50 \mathrm{~nm})$ into a saturated solution of $\mathrm{AlCl}_{3}$ in acetone for $24 \mathrm{~h}$ at room temperature, followed by multiple rinsing in pure acetone. All steps were done in air-free conditions.

Electrical Measurements. Electrical measurements were carried out at room temperature in the air using two Keithley source measurement units, one Keithley 2611A for the drain/source contacts and one Keithley 2400 for the gate/source contact. In order to calculate FET performance data, the current-voltage characteristics in the different operating regimes of the FETs were described analytically assuming the gradual channel approximation. ${ }^{38}$

\section{RESULTS AND DISCUSSION}

Solution-phase Exchange via Flocculation. PbSe NCs of 4 to $9 \mathrm{~nm}$ capped with long, electrically insulating OA surfactants were dispersed in desired concentrations in the nonpolar solvent hexane. The concentrations were determined according to their size-dependent extinction coefficients as reported by Dai et al. ${ }^{39}$ To exchange the organic ligands, we used mild flocculation of $\mathrm{NCs}$ leading to a fast and efficient ligand replacement (Figure 1A). Ligand exchange on CdSe crystallites was first demonstrated by replacing trioctylphosphine oxide and trioctylphosphine molecules with an excessive amount of pyridine as weakly coordinating ligands. ${ }^{40}$ Gaponik et al. used acetone as a "surfactant" to facilitate the transfer of CdTe NCs through the surface boundary via the reduction of the surface tension at the polar-nonpolar interface. ${ }^{41}$ Later, the Murray group carried out the ligand exchange via the destabilization of NCs using $\mathrm{NH}_{4} \mathrm{SCN}$ dissolved in acetone. ${ }^{15}$

In the present work, we used acetone as an "intermediate" solvent being compatible with two immiscible phases. Generally, the ligand exchange relies on the effect of mass action that includes the exposure of the NCs to a large excess of new ligands, i.e., $\mathrm{I}^{-}$ions. This process can be accelerated by the gentle destabilization of the NCs, e.g., by the addition of a solvent with a relatively high dielectric constant (a so-called nonsolvent). The destabilization itself creates more favorable conditions for the leaving of the $\mathrm{OA}$ from the particles and for increasing the exchange rate. Acetone with its moderate static dielectric constant $\left(\varepsilon_{25^{\circ} \mathrm{C}} \sim 21\right)$ can be considered as a nonsolvent for the destabilization of only relatively concentrated solutions of NCs. At the same time, we noticed that the efficiency of the phase transfer is much higher when relatively diluted solutions of $\mathrm{NCs}$ are used. However, since $\mathrm{NH}_{4} \mathrm{I}$ is badly soluble in acetone, only scanty concentrations of the competitive $\mathrm{I}^{-}$ions are achievable, and efficient ligand exchange is challenging in both concentrated and diluted solutions.

At this stage, we introduce mixtures of acetone $\left(\varepsilon_{25^{\circ} \mathrm{C}} \sim 21\right)$ and MFA $\left(\varepsilon_{25^{\circ} \mathrm{C}} \sim 180\right)$ which appear to be good solvents for $\mathrm{NH}_{4} \mathrm{I}$ and simultaneously act as strong destabilizers for the $\mathrm{NCs}$, which enables both quick destabilization and efficient ligand exchange even in very diluted colloidal solutions. The high affinity of the iodide ligands to the NC surface prospers the efficiency of the ligand replacement. Bromide and chloride ions were also able to replace the OA molecules. However, the colloidal $\mathrm{PbSe}$ system remained stable only with an excess of $\mathrm{Br}^{-}$while $\mathrm{Cl}^{-}$ions could not form stable PbSe colloids.

For the prediction of the binding affinity between a given ligand and a given NC, the concept of hard and soft acids and bases, developed by Pearson, ${ }^{42}$ may be valuable and has already been applied to colloidal nanoparticles. ${ }^{14}$ According to this concept, soft acidic $\mathrm{Pb}^{2+}$ centers (which are bound to $\mathrm{Se}^{2-}$ species, softening cation sites) should preferably bind to the soft basic $\mathrm{I}^{-}$, bind relatively worse to $\mathrm{Br}^{-}$, and bind the worst to hard $\mathrm{Cl}^{-}$centers. Acetone as an aprotic solvent is better in the ligand exchange as compared to methanol or ethano, although the latter two can also be used. Both of the mentioned alcohols are protic, in contrast to acetone, which may inhibit the ligand exchange due to desorption of the halide from the PbSe NCs surface and a possible removal of electrophilic centers from the NC surface under an attack of a protic solvent. ${ }^{43}$ Recently, chloride-terminated $\mathrm{PbS}$ NCs have been shown to be very susceptible to a protic attack. ${ }^{30}$

The proper choice of the cations is important due to their influence on the electrical and optical properties of the NCs. We have to note that our method of ligand exchange is also applicable to the formation of stable PbSe NCs in MFA if either bulky tetramethylammonium iodide or tiny potassium iodide ligands are used. It is well-known, however, that $\mathrm{K}^{+}$ions may create local electrostatic barriers around NPs and behave as electron scattering centers. ${ }^{14}$ In its own turn, the big, nonvolatile tetramethylammonium will lead to increasing the distance between the NCs. For these reasons, all results presented below are obtained with ammonium cations, which are volatile, small, and do not suppress electron transport.

Figure $1 \mathrm{~B}$ presents the absorption and normalized emission spectra of $4.0 \mathrm{~nm} \mathrm{PbSe} \mathrm{NCs,} \mathrm{stabilized} \mathrm{with} \mathrm{OA} \mathrm{in} \mathrm{TCE} \mathrm{and} \mathrm{I}^{-}$ in PC. The absorption spectra of the iodide-exchanged PbSe $\mathrm{NCs}$ in PC (red line) show discrete resonances being characteristic for transitions between quantum-confined holes and electron states, here with a slight hypsochromic shift after ligand exchange. The iodide-stabilized $\mathrm{PbSe} \mathrm{NCs}$ exhibit excitonic PL with a quantum efficiency ca. 3 times lower than that of the initial PbSe NCs capped with $\mathrm{OA}$ (as was determined by calculating spectrally integrated photon flux at the detector at common excitation wavelength).

ATR-FTIR spectroscopy of dried, iodide capped PbSe NCs confirms an almost complete exchange of the initial $\mathrm{OA}$ with iodide ligands (Figure 2A) as seen from the disappearance of the characteristic $\mathrm{C}-\mathrm{H}$ and $\mathrm{O}-\mathrm{H}$ stretching modes $(2800-$ $\left.3000 \mathrm{~cm}^{-1}\right)$, the $\mathrm{C}-\mathrm{H}$ bending vibrations, and the carboxylic $\mathrm{C}-\mathrm{O}$ and the vinyl $\mathrm{C}=\mathrm{C}$ stretching modes $\left(800-1500 \mathrm{~cm}^{-1}\right)$. Weak signals at $\sim 3400 \mathrm{~cm}^{-1}$ and in the fingerprint area could 


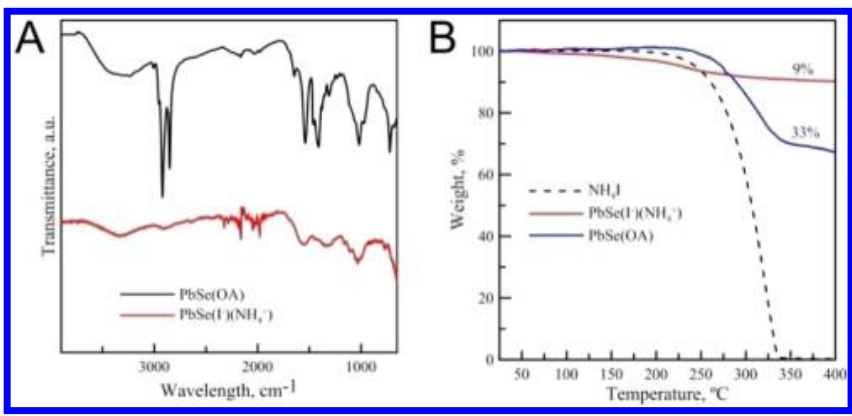

Figure 2. (A) FTIR spectra of $4.0 \mathrm{~nm}$ PbSe NCs capped with OA and with iodide (vertically shifted for clarity). (B) Thermogravimetric scans for $\mathrm{NH}_{4} \mathrm{I}$ (dashed line), for $4.0 \mathrm{~nm}$ PbSe NCs stabilized with $\mathrm{OA}$ (blue line) and with iodide (red line).

rise from the vibrational modes of $\mathrm{NH}_{4}^{+}$cations. ${ }^{44}$ The thermogravimetric scans (Figure 2B) for $4.0 \mathrm{~nm} \mathrm{PbSe} \mathrm{NCs}$ capped with $\mathrm{I}^{-}$show a total weight loss of $9 \%$, which is significantly smaller than that of $33 \%$ for PbSe stabilized with $\mathrm{OA}$. The abrupt decrease in the weight of the $\mathrm{PbSe} \mathrm{NC}$ powder appeared close to the decomposition temperature of $\mathrm{NH}_{4} \mathrm{I}$ (start at $T \sim 230{ }^{\circ} \mathrm{C}$ ). The gradual decrease in the weight for $\mathrm{PbSe}$ NCs stabilized with $\mathrm{I}^{-}$ions may be attributed to the highboiling solvent (PC) still sticking to the NCs and not being completely removed during the drying of the $\mathrm{PbSe}$ powder.

To get a full picture of the changing chemical composition of the NC surface, we performed a comparative XPS study of 4.0 $\mathrm{nm} \mathrm{PbSe}$ NCs before and after surface modification with ammonium iodide. The survey XPS spectrum of both samples is presented in Figure S1. The high-resolution XPS spectrum in the range of $4 \mathrm{f5} / 2-4 \mathrm{f} 7 / 2$ spin-orbit doublet of lead (Figure S2A) can be modeled with two components centered for the $4 \mathrm{f} 7 / 2$ peak at 136.6 and $137 \mathrm{eV}$, respectively. Based on previous XPS studies of PbSe NCs, ${ }^{45}$ we relate these two $\mathrm{Pb}^{2+}$ states to $\mathrm{Pb}-\mathrm{Se}$ and $\mathrm{Pb}-\mathrm{O}$ bonding, respectively. After ligand exchange with iodide species, the peak becomes sharper and shifts to higher binding energies (e.g., the value is $137.8 \mathrm{eV}$ for the $4 \mathrm{f} 7 / 2$ peak; Figure S2B). This shift can be assigned to a $\mathrm{Pb}-\mathrm{I}$ adduct formation on the $\mathrm{NC}$ surface, as the $\mathrm{Pb}-\mathrm{I}$ bonding is known to result in a higher binding energy of the $\mathrm{Pb}$ core electrons compared to $\mathrm{Pb}-\mathrm{Se}$ and $\mathrm{Pb}-\mathrm{O}$ bonds. ${ }^{18}$ The iodide $3 \mathrm{~d} 3 / 2$ and $3 \mathrm{~d} 1 / 2$ peaks are observed for the iodide-treated sample at 619 and $630.5 \mathrm{eV}$, respectively (Figure S3A), which are in agreement with binding energies of $\mathrm{I}$ atoms in bulk $\mathrm{PbI}_{2}{ }^{46}$ The presence of the nitrogen signal only in the spectrum of iodide capped $\mathrm{PbSe} \mathrm{NCs}$ (Figure S3B) is also related to the $\mathrm{NH}_{4} \mathrm{I}$ ligands. It is noted that a sharpening of the XPS lines in the iodide-treated sample is observed for the Se species as well (Figure S4). However, unlike an oxidation-induced broadening of the $\mathrm{Pb}$ spectrum of the oleic-acid-stabilized NCs (Figure S2A), no features of Se oxidation are observed which would be expected in the range of 58-60 eV (Figure S4A). ${ }^{45}$ The nature of the narrowing of the peaks after the ligand exchange will be investigated in more detail in the future.

TEM images of the PbSe NCs capped with $\mathrm{I}^{-}$ions confirmed the retention of their size and their narrow size distribution after the ligand exchange (Figure 3). EDX spectroscopy made for $5.2 \mathrm{~nm}$ NCs from six spots unveiled the average atomic ratio of the elements as Pb:Se:I = 1.24:1.00:0.31. A representative EDX spectrum is presented in Figure S5. These data indicate that the lead selenide nanocrystals were nonstoichiometric with an excess of electrophilic lead centers which facilitate the

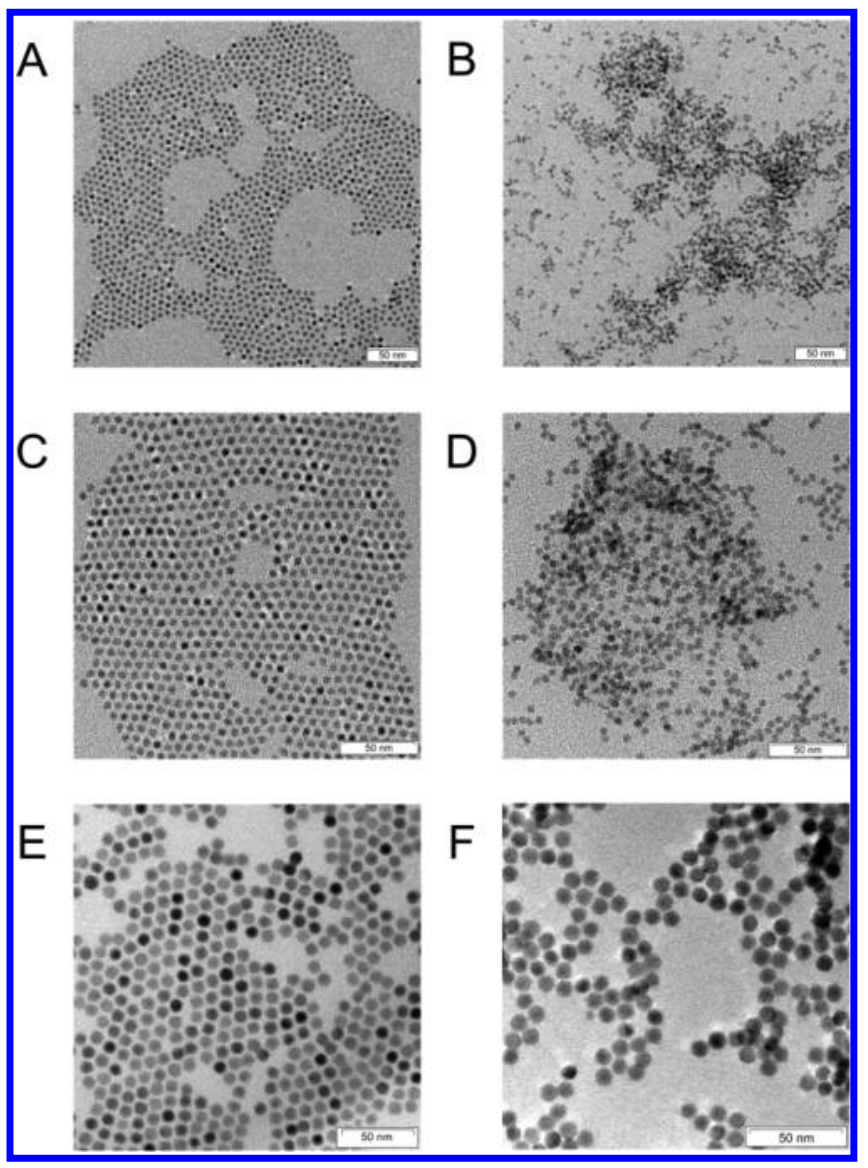

Figure 3. TEM images of $5.2 \mathrm{~nm}(\mathrm{~A}, \mathrm{~B}), 6.0 \mathrm{~nm}(\mathrm{C}, \mathrm{D})$, and $8.9 \mathrm{~nm}$ (E,F) PbSe nanoctystals, stabilized with OA (left) and iodide (right), respectively.

binding of the nucleophilic iodide ions. The amount of the iodide species was ca. 12 atom \% in the PbSe after ligand exchange.

The true colloidal nature of $\mathrm{I}^{-}$-capped $\mathrm{PbSe} \mathrm{NCs}$ was also confirmed by the monomodal particle population observed in the dynamic light scattering (DLS) measurements (Figure $\mathrm{S} 6 \mathrm{~A}) . \mathrm{I}^{-}$-capped NCs are negatively charged with a $\xi$-potential of ca. $-28 \mathrm{mV}$, as can be seen from the electrophoretic measurements of 4.0 and $6.0 \mathrm{~nm} \mathrm{PbSe} \mathrm{NCs} \mathrm{in} \mathrm{PC} \mathrm{(Figure}$ S6B).

The X-ray diffraction (XRD) pattern of the $5.3 \mathrm{~nm} \mathrm{I}^{-}$-capped $\mathrm{PbSe}$ NCs (Figure 4) is similar to that of the originally capped NCs with no additional reflections from I-containing phases or other possible impurities. However, the reflected intensities from the crystallographic planes (200) and (400) are sufficiently enhanced. A preferred orientation of the $\mathrm{PbSe}$ NCs along the $\langle 100\rangle$ direction during drying of the concentrated solutions may explain this observation. ${ }^{47}$

Stability of lodide-Capped PbSe NCs. In order to address the problem of the air susceptibility of PbSe NCs, we studied their stability before and after the ligand exchange under ambient conditions. It has been recently proposed that $\mathrm{PbSe}$ NCs show size-dependent air instability due to the fast oxidation of the $\{100\}$ facets which are typically less passivated by the $\mathrm{OA}^{48}$ It was also shown that in addition to OA molecules, $\mathrm{NH}_{4} \mathrm{X}(\mathrm{Cl}, \mathrm{Br}, \mathrm{I})$ passivates the $\{100\}$ facets of $\mathrm{PbSe}$ NCs, which leads to enhanced PL quantum yields and improved air stability in nonpolar solvents. ${ }^{20}$ To check if 


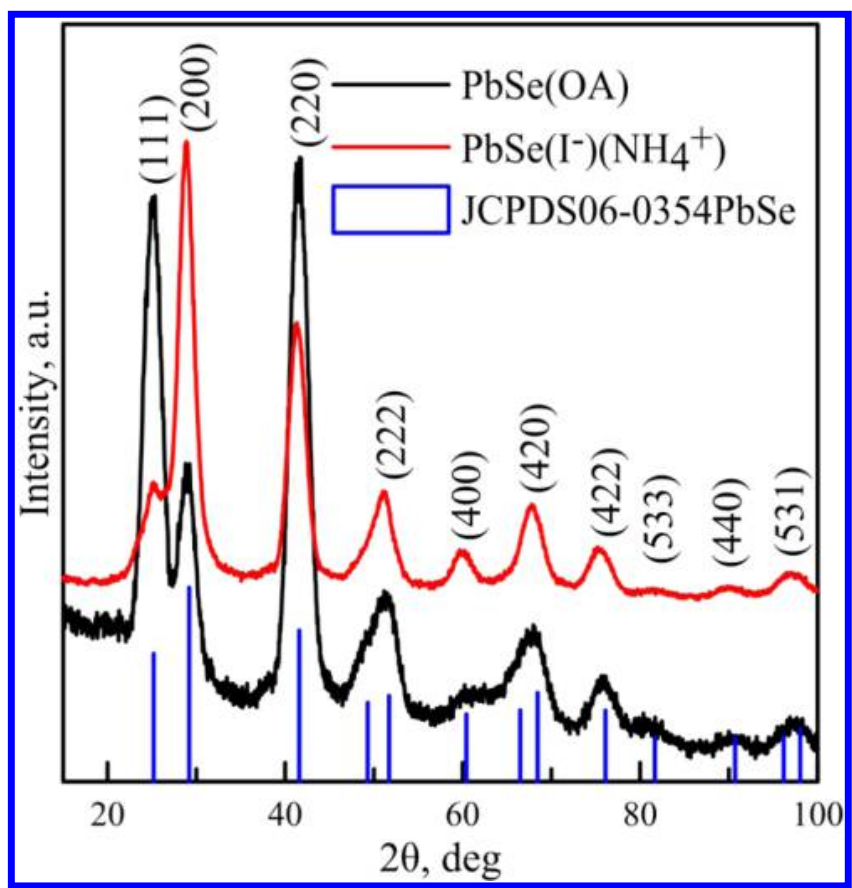

Figure 4. XRD patterns of $5.3 \mathrm{~nm}$ PbSe NCs before and after ligand exchange with all reflections expected for bulk rock-salt structure confirming that neither phase transitions nor formation of a new phase takes place. The strong increased relative ratio of intensities from $(200) /(111)$ planes in the Bragg configuration after the ligand exchange is probably related to the preferable alignment of NCs along the $\langle 100\rangle$ axis.

iodide species alone (without OA) can passivate $\{100\}$ facets, we compare the air stability after and before the ligand exchange for $5.3 \mathrm{~nm}$ PbSe NCs (Figure S7).

As seen from Figure S7, keeping OA stabilized NC solutions under air for only 1 to 3 days results in a noticeable blue shift of the absorption features of the PbSe NCs which is typically associated with their degradation. ${ }^{45}$ On the other hand, an only very slight spectral shift is observed for iodide passivated NCs even after 7 days under air. However, we cannot exclude an influence of the different solubility of oxygen in TCE and PC on the observed phenomena. Nevertheless, solid state films prepared from iodide passivated $\mathrm{PbSe} \mathrm{NCs}$ in $\mathrm{PC}$ show a considerably higher environmental stability as compared to their OA passivated counterparts.

It is advised to highlight the importance of the solvent for the stabilization of nanoparticles with tiny charged ligands. ${ }^{16}$ Both MFA and FA are suitable for obtaining colloidal solutions of iodide-capped NCs at high concentrations without a noticeable precipitation for over 6 months. At the same time, diluted solutions (typically below $5 \mathrm{mg} / \mathrm{mL}$ ) tend to precipitate quickly within minutes. Both solvents have high dielectric constants $\varepsilon_{\mathrm{r}}$ (180 and 110, respectively) leading to decreasing the potential energy of charged NCs and increasing their stability. But both solvents are also characterized by a high Lewis acidity, i.e., the capability of strongly solvating anions which results in precipitation upon dilution. ${ }^{49,50}$ Solvents such as PC and DMF with moderate dielectric constants, low Lewis acidity, and high Lewis basicity may form stable solutions of $\mathrm{I}^{-}$-stabilized $\mathrm{PbSe}$ in a wide range of concentrations (Figure S8). This, thus, provides more flexibility for handling and processing of $\mathrm{I}^{-}$capped PbSe NCs. It is important to note that neither FA nor
DMF could stabilize iodide-capped CdSe NCs obtained via a phase transfer procedure. ${ }^{17}$

Our attempts to obtain stable solutions in water $(\mathrm{pH} \sim 7$; $\mathrm{pH} \sim 9.5)$ failed due to a protic attack and the high Lewis acidity of water, even at high $\mathrm{pH} .^{12}$ The absorbance spectra in Figure S8 show a blue shift (for PC) and a red shift (for the other solvents) for the same $\mathrm{PbSe}$ NCs capped with $\mathrm{I}^{-}$. These kinds of spectral shifts are typically explained by the electron and hole wave functions leaking into the ligand shell. ${ }^{13}$ In the case of the same ligand (our case), the nature of the shifts is much likely related to the dielectric properties of the surrounding environment rather than a partial leakage of the wave function. ${ }^{7,51}$

Transport Characteristics of PbSe NC Solids. It is expected that replacing the bulky and insulating OA chains with much smaller $\mathrm{I}^{-}$ligands facilitates the charge transport between PbSe NCs. ${ }^{52}$ Here, we studied the coupling between $\mathrm{I}^{-}$-capped PbSe NCs by analyzing the optical absorption and measuring carrier mobilities in NC films under ambient conditions.

Figure S9 compares absorption spectra of various $\mathrm{PbSe} \mathrm{NCs}$ in colloidal solutions and in the form of close-packed films. There are no meaningful shifts of absorption maxima for the films of $\mathrm{PbSe} \mathrm{NCs}$ capped with $\mathrm{I}^{-}$as compared to the same nanoparticles in solutions. Higher energy barriers created by HOMO and LUMO orbitals of the new ligands, as well as formation of glassy films with short-range ordering leading to localization of electron and hole wave functions on individual NCs, may explain this result. ${ }^{53,54}$ The observation of band edge $\mathrm{PL}$ from $\mathrm{I}^{-}$-capped $\mathrm{PbSe} \mathrm{NCs}$ confirms that $\mathrm{I}^{-}$ligands do not introduce midgap states, which may serve as fast nonradiative recombination channels. The absorption band of the first electronic transition of NC solids was slightly broadened compared to the dispertion of isolated NCs, which is further decreasing with an increase in the NC size $(10 \mathrm{meV}$ for $4.0 \mathrm{~nm}$,

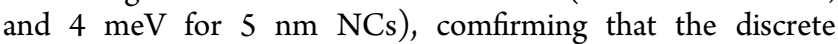
quantum confined wave functinon is mainly localized on individual particles, despite being in close proximity to each other.

The film fabrication (except for ALD prepared films) was performed in air. In spite of the enhanced air-stability of PbSe NCs capped with $\mathrm{I}^{-}$, there is still oxidation of selenium species possible, especially in the thin films, resulting in a deterioration of the properties of the quantum dot solids which may be reflected in minor deviations observed in the spectra.

In a single-step low-temperature solution-based process, we fabricated uniform, crack-free, glassy close-packed iodide stabilized PbSe NC thin-film with a thickness of $\sim 50 \mathrm{~nm}$. Subsequently, this was used as a semiconductor active layer in a field-effect transistor. The as-deposited OA-stabilized PbSe NC solids showed insulating behavior with a conductivity of $\sim 10^{-10}$ $\mathrm{S} / \mathrm{cm}$, whereas the $\mathrm{I}^{-}$-capped $\mathrm{PbSe} \mathrm{NC}$ solids showed no gate modulation and an increased conductivity of $\sim 10^{-4} \mathrm{~S} / \mathrm{cm}$. The $\mathrm{I}^{-}$ions can be considered both as capping ligands for the stabilization of the PbSe NCs as well as an n-type doping agent. Smaller-bandgap materials with low ionization potentials are strongly prone to oxidation. Unfortunately, our setup did not allow us to perform the same measurement in air-free conditions, which would give more reliable data for n-type doped PbSe NCs. To improve the air stability and reduce the density of surface states, we implemented the solution treatment with $\mathrm{AlCl}_{3}$ or $\mathrm{ALD}$ of $\mathrm{Al}_{2} \mathrm{O}_{3}$.

The ALD infilling of close-packed films of $4.0 \mathrm{~nm}$ iodide capped $\mathrm{PbSe} \mathrm{NCs}$ at $87^{\circ} \mathrm{C}$ with an amorphous $\mathrm{Al}_{2} \mathrm{O}_{3}$ layer led 


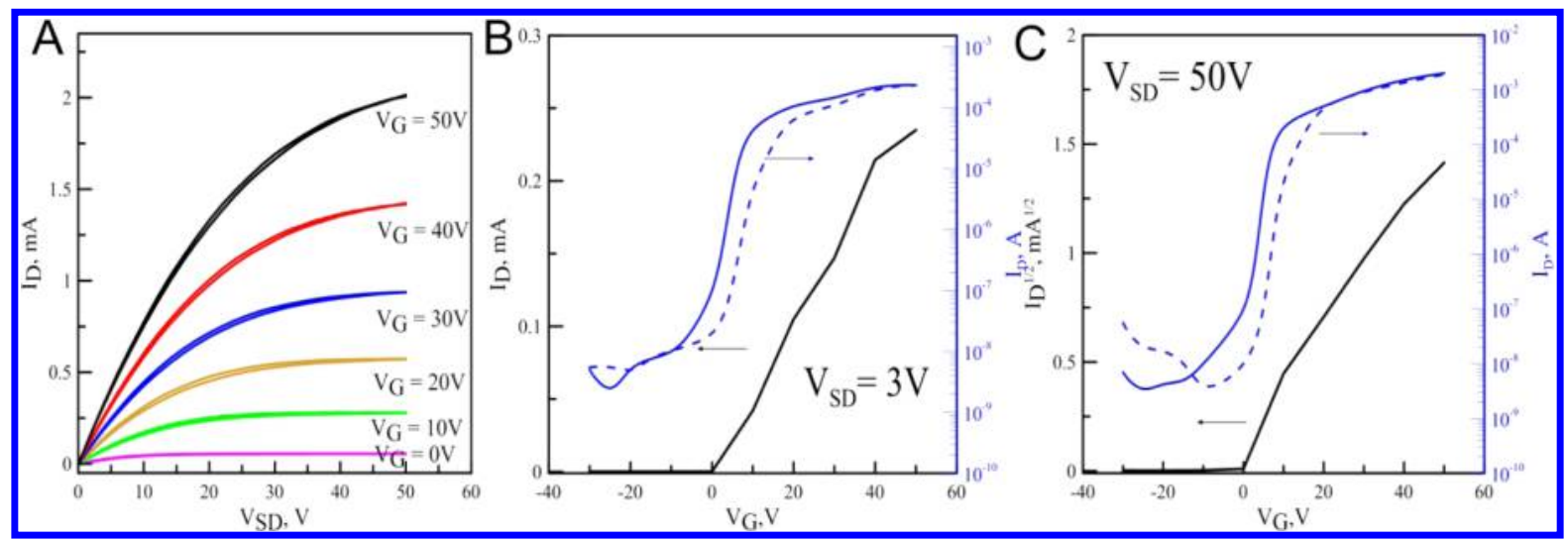

Figure 5. Representative output (A) and transfer characteristics of the $\mathrm{n}$-channel field-effect transistor based on PbSe NC solids after the combined $\mathrm{Al}_{2} \mathrm{O}_{3}$ and heat treatment in the linear (B) and the saturation (C) regimes. Solid and dashed lines correspond to forward and reverse applied gate bias, respectively.

to a dramatic increase of air stability and charge transport characteristics, named below. The thickness of the alumina layer of $10 \mathrm{~nm}$ was chosen based on the data presented by Law et al., who reported that $\sim 5 \mathrm{~nm}$ of $\mathrm{Al}_{2} \mathrm{O}_{3}$ was sufficient to effectively infill $\mathrm{S}^{2-}$ capped $\mathrm{PbSe} \mathrm{NC}$ films. ${ }^{26}$ We added an additional $5 \mathrm{~nm}$ to guarantee complete infiltration. Figure 5 shows the representative output and transfer characteristics of this ALD protected film. The gradual channel approximation was used to extract valuable data from the current-voltage characteristics.

We observed an n-type gate effect with a current modulation of $I_{\text {on }} / I_{\text {off }} \sim 10^{4}$, a subthreshold swing $\left(S^{-1}\right)$ of $4 \mathrm{~V} / \mathrm{dec}$, and a threshold voltage of $V_{\text {th }}=-3.8 \mathrm{~V}$. The linear and saturation mobilities measured for six devices were $\mu_{\text {lin }}=(2.1 \pm 0.3) \mathrm{cm}^{2} /$ $(\mathrm{V} \cdot \mathrm{s})\left(V_{\mathrm{SD}}=3 \mathrm{~V}\right)$ and $\mu_{\mathrm{sat}}=(2.9 \pm 0.4) \mathrm{cm}^{2} /(\mathrm{V} \cdot \mathrm{s})\left(V_{\mathrm{SD}}=50\right.$ $\mathrm{V})$, respectively. Both mobilities are quite similar and independent of the source-drain electric field. These values are comparable with the linear electron mobilities reported for $\mathrm{PbSe}$ stabilized with $\mathrm{S}^{2-}$ and further passivated with $\mathrm{Al}_{2} \mathrm{O}_{3}$ and $\mathrm{PbCl}_{2}$, namely $\sim 7 \mathrm{~cm}^{2} /(\mathrm{V} \cdot \mathrm{s})$ and $5 \mathrm{~cm}^{2} /(\mathrm{V} \cdot \mathrm{s})$, respectively. ${ }^{26,27}$

After combined ALD and heat treatment, the PbSe NC solids still show a hysteresis behavior. This instability in the TFT performance may be attributed to a charge trapping in the semiconductor, gate insulator, and/or interface traps between them. Indeed, we used a relatively thick $\mathrm{SiO}_{2}$ gate dielectric with hydroxyl groups, which may act as electron traps. Moreover, high operating voltages from $-30 \mathrm{~V}$ to $+50 \mathrm{~V}$ were applied. We also cannot exclude the presence of the trap states even after the ALD passivation. Among others, conduction-band-tail states and deep-gap states may diminish the mobility and decrease the stability. For example, the nonlinearity of $I_{\mathrm{D}}-V_{\mathrm{GS}}$ at low $V_{\mathrm{SD}}$, which is seen in Figure $5 \mathrm{~B}$, is likely to be associated with band-tail states. ${ }^{55}$

The electronic structure of the NC solids is retained after the combined $\mathrm{Al}_{2} \mathrm{O}_{3}$ and heat treatment, reflected in a red shift and a broadened $1 S_{h}-1 S_{e}$ excitonic peak, showing features of increased interparticle coupling (Figure 6). Since lead chalcogenides can ripen and sinter at moderate temperatures, we measured the average grain size and surface morphology of the films after heat treatment using XRD and SEM techniques. The calculated average grain size increases from 4.2 to $4.8 \mathrm{~nm}$ $\left(T=90{ }^{\circ} \mathrm{C}\right)$ and then only to $5.0 \mathrm{~nm}\left(T=130{ }^{\circ} \mathrm{C}\right.$; Figure S10), which excludes the sintering of the NCs into a NC solid. SEM images have not shown any significant changes in the NC film morphology on the micrometer scale (Figure S11). Both

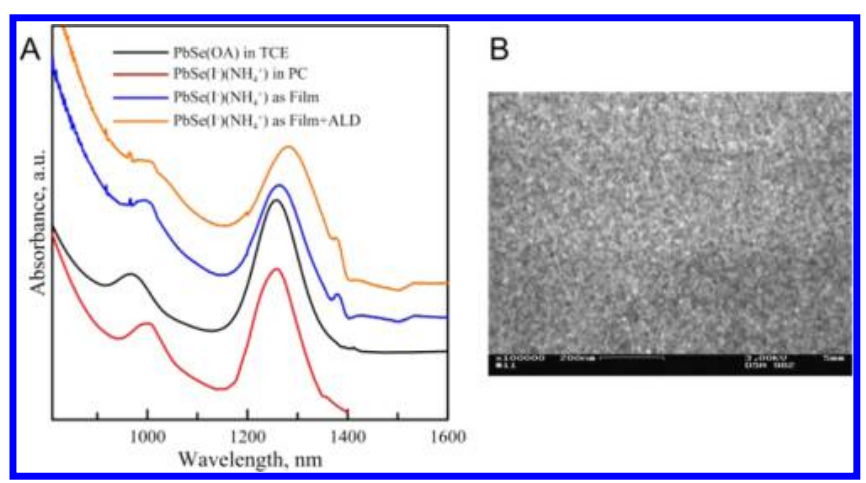

Figure 6. (A) Absorption spectra of $4.0 \mathrm{~nm}$ PbSe quantum dot solids before and after the ALD treatment, together with those of solutions of the quantum dots before and after the ligand exchange. (B) SEM image of a PbSe film on silicon substrate at room temperature before the ALD infilling.

observations imply that iodide ligands may form an ion diffusion blocking layer, inhibiting crystal growth. ${ }^{56}$ It is mentioned that a short $(\sim 15 \mathrm{~s})$ contact of the samples with air during their transfer from the glovebox to the ALD appliance was not avoidable in our case. This contact, although not crucial, may still be responsible for some deviation of the film characteristics as compared to those prepared under strictly air-free conditions. Contrarily, infilling the same PbSe system with $\mathrm{HfO}_{2}$ has not improved the device performance, compared to untreated $\mathrm{PbSe}$ solids. This emphasizes the role of the aluminum species in the efficient passivation of surface dangling bonds, inevitably induced after ligand exchange. Thus, ALD coating with both $\mathrm{HfO}_{2}(\varepsilon \sim 25)$ and $\mathrm{Al}_{2} \mathrm{O}_{3}(\varepsilon \sim 9)$ probably does not alter the gate oxide; neither does it lower the tunnel barrier height with a reduction of the $\mathrm{NC}$ charging energy. ${ }^{57}$ The possible gate stacking formation $\left(\mathrm{SiO}_{2} / \mathrm{Al}_{2} \mathrm{O}_{3}\right.$ or $\mathrm{SiO}_{2} /$ $\mathrm{HfO}_{2}$ ) would lead to slight changes in the total gate capacitance without a dramatic improvement of TFT characteristics. Both materials are very wide bandgap insulators $\left(E_{\mathrm{g}}\left(\mathrm{HfO}_{2}\right) \sim 5.7 \mathrm{eV}\right.$, $\left.E_{\mathrm{g}}\left(\mathrm{Al}_{2} \mathrm{O}_{3}\right) \sim 8.7 \mathrm{eV}\right),{ }^{57}$ which cannot lower the tunnel barrier for charge transport. The charging energy of $4.0 \mathrm{~nm} \mathrm{PbSe} \mathrm{NCs}$ in the glassy NC solids is $15-23 \mathrm{meV}$, which is less than the thermal energy $(\sim 26 \mathrm{meV}) .^{23}$ This rules out a decreased charging and excludes impact for room-temperature charge transport. 
Opposite to the ALD infilling, the solution treatment with $\mathrm{AlCl}_{3}$ led to the formation of $\mathrm{PbSe} \mathrm{NC}$ solids with p-type behavior with output and transfer characteristics presented in Figure 7 . The calculated linear hole mobility reaches $\mu_{\text {lin }}=3.7$

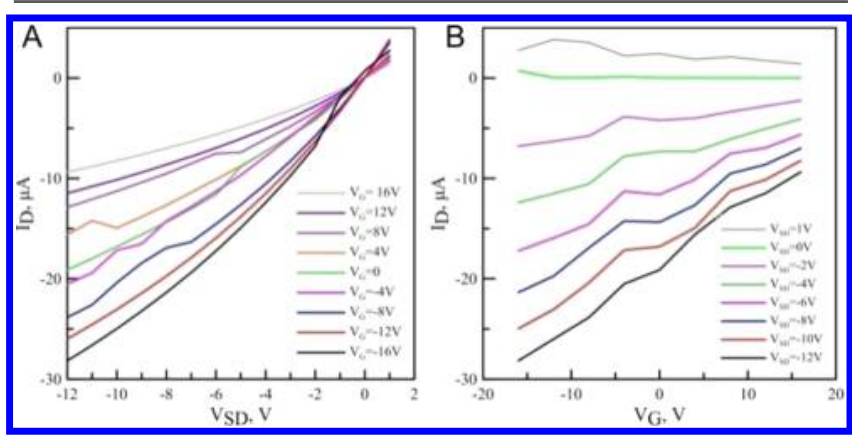

Figure 7. $\mathrm{I}-\mathrm{V}$ measurement of $\mathrm{AlCl}_{3}$-treated $\mathrm{PbSe}$ iodide stabilized nanocrystal films. After c-ALD activation, these films behave as conductive p-type nanocrystal FETs with the output (A) and transfer (B) characteristics.

$\times 10^{-2} \mathrm{~cm}^{2} /(\mathrm{V} \cdot \mathrm{s})$. Here, it is noted that this p-type conductivity for $\mathrm{I}^{-}$-stabilized $\mathrm{PbSe} \mathrm{NC}$ solids additionally passivated with $\mathrm{Al}^{3+}$ ions is unexpected and remains, thus far, unclear. A possible explanation may be an incomplete passivation of the surface of the $\mathrm{NCs}$ by the $\mathrm{Al}^{3+}$ ions allowing oxygen to penetrate and change the main type of carries.

It might be concluded that the very reactive $\mathrm{Al}\left(\mathrm{CH}_{3}\right)_{3}$ used in the ALD passivates the surface traps of the NCs better than the $\mathrm{Al}^{3+}$ ions used in the solution treatment. Moreover, the higher temperature used in the ALD $\left(87^{\circ} \mathrm{C}\right)$ versus room temperature might be responsible for an enhanced coupling between the NCs in the films.

The electrical characteristics of the low-temperature solutionbased iodide-capped PbSe NC solids described above were obtained without full optimization. It is clear that the device fabrication and the characterization performed under air-free conditions, the utilization of electrodes with appropriate metal work functions, the replacement of $\mathrm{SiO}_{2}$ with $\mathrm{OH}$-free gate dielectrics, and the control of the nanostructuring via an optimized annealing will lead to improved transport characteristics and will offer further options for a rational material design.

\section{CONCLUSIONS}

We report the successful modification of lead selenide NCs. The initial strongly insulating long oleic acid molecules are replaced with short, compact iodide ions via a mild flocculation of PbSe NCs leading to the formation of stable colloidal solutions with various polar solvents in a broad range of concentrations. The iodide capping preserves the electronic structure and the photophysical properties of PbSe NCs. These iodide-capped PbSe NCs thus add favorably to the effort of obtaining stable solutions of all-inorganic capped lead chalcogenides. Ammonium iodide used for capping is a small, inorganic, and environmentally friendly ligand, providing short interparticle distances in NC solids maintaining pronounced excitonic absorption features which are crucial for the implementation into electronic and optoelectronic applications. The solution deposited and further ALD protected $4.0 \mathrm{~nm}$ $\mathrm{PbSe}$ NC solids exhibit improved transport characteristics with electron mobilities in the linear and saturation regimes reaching $\sim 2$ and $\sim 3 \mathrm{~cm}^{2} /(\mathrm{V} \cdot \mathrm{s})$, respectively. These results open opportunities for the low-cost and low-temperature fabrication of NC thin films for transistor, solar cell, and photodetector applications.

\section{ASSOCIATED CONTENT}

\section{Supporting Information}

XPS, EDX, DLS, and XRD data; STEM and SEM images of the films; stability tests; and NIR absorbance spectra of PbSe NCs in various solvents. The Supporting Information is available free of charge on the ACS Publications website at DOI: 10.1021/ acs.chemmater.5b00793.

\section{AUTHOR INFORMATION}

\section{Corresponding Author}

*E-mail: Nikolai.Gaponik@chemie.tu-dresden.de.

\section{Notes}

The authors declare no competing financial interest.

\section{ACKNOWLEDGMENTS}

This work was supported by the Deutsche Forschungsgemeinschaft (DFG) within the Cluster of Excellence "Center for Advancing Electronics Dresden.” Joint experiments were partially supported by the EU-FP7 Network of Excellence N4E, and in part by BMBF TUR 09/001 and TUBITAK EEEAG 112E183. We thank S. Goldberg for SEM imaging, Nasser Mohamed-Noriega for help in DLS measurements, and Burak Güzeltürk and Kıvanç Güngör for fruitful discussions of the device fabrication. H.V.D. acknowledges additional support from TUBA-GEBIP and ESF EURYI. V.S. and N.G. thank Dmitri V. Talapin for discussions and useful advice.

\section{REFERENCES}

(1) Talapin, D. V.; Lee, J.-S.; Kovalenko, M. V.; Shevchenko, E. V. Prospects of Colloidal Nanocrystals for Electronic and Optoelectronic Applications. Chem. Rev. 2010, 110, 389-458.

(2) Wise, F. W. Lead Salt Quantum Dots: The Limit of Strong Ouantum Confinement. Acc. Chem. Res. 2000, 33, 773-780.

(3) Romero, H.; Drndic, M. Coulomb Blockade and Hopping Conduction in PbSe Quantum Dots. Phys. Rev. Lett. 2005, 95, 156801.

(4) Pietryga, J. M.; Schaller, R. D.; Werder, D.; Stewart, M. H.; Klimov, V. I.; Hollingsworth, J. A. Pushing the Band Gap Envelope: Mid-Infrared Emitting Colloidal PbSe Quantum Dots. J. Am. Chem. Soc. 2004, 126, 11752-11753.

(5) Kang, I.; Wise, F. W. Electronic Structure and Optical Properties of PbS and PbSe Quantum Dots. J. Opt. Soc. Am. B 1997, 14, 1632.

(6) Du, H.; Chen, C.; Krishnan, R.; Krauss, T. D.; Harbold, J. M.; Wise, F. W.; Thomas, M. G.; Silcox, J. Optical Properties of Colloidal PbSe Nanocrystals. Nano Lett. 2002, 2, 1321-1324.

(7) Talapin, D. V.; Murray, C. B. PbSe Nanocrystal Solids for N- and P-Channel Thin Film Field-Effect Transistors. Science 2005, 310, 8689.

(8) Wang, R. Y.; Feser, J. P.; Lee, J.-S.; Talapin, D. V.; Segalman, R.; Majumdar, A. Enhanced Thermopower in PbSe Nanocrystal Quantum Dot Superlattices. Nano Lett. 2008, 8, 2283-2288.

(9) Jiang, Z.; You, G.; Wang, L.; Liu, J.; Hu, W.; Zhang, Y.; Xu, J. Solution-Processed High-Performance Colloidal Quantum Dot Tandem Photodetectors on Flexible Substrates. J. Appl. Phys. 2014, $116,084303$.

(10) Zhang, J.; Gao, J.; Church, C. P.; Miller, E. M.; Luther, J. M.; Klimov, V. I.; Beard, M. C. PbSe Quantum Dot Solar Cells with More than 6\% Efficiency Fabricated in Ambient Atmosphere. Nano Lett. 2014, 14, 6010-6015.

(11) Kovalenko, M. V.; Spokoyny, B.; Lee, J.; Scheele, M.; Weber, A.; Perera, S.; Landry, D.; Talapin, D. V. Semiconductor Nanocrystals Functionalized with Antimony Telluride Zintl Ions for Nanostructured Thermoelectrics. J. Am. Chem. Soc. 2010, 132, 6686-6695. 
(12) Kovalenko, M. V.; Bodnarchuk, M. I.; Zaumseil, J.; Lee, J. S.; Talapin, D. V. Expanding the Chemical Versatility of Colloidal Nanocrystals Capped with Molecular Metal Chalcogenide Ligands. J. Am. Chem. Soc. 2010, 132, 10085-10092.

(13) Kovalenko, M. V.; Scheele, M.; Talapin, D. V. Colloidal Nanocrystals with Molecular Metal Chalcogenide Surface Ligands. Science 2009, 324, 1417-1420.

(14) Nag, A.; Kovalenko, M. V.; Lee, J.-S.; Liu, W.; Spokoyny, B.; Talapin, D. V. Metal-Free Inorganic Ligands for Colloidal Nanocrystals: $\mathrm{S}^{2-}, \mathrm{HS}^{-}, \mathrm{Se}^{2-}, \mathrm{HSe}^{-}, \mathrm{Te}^{2-}, \mathrm{HTe}^{-}, \mathrm{TeS}_{3}{ }^{2-}, \mathrm{OH}^{-}$, and $\mathrm{NH}_{2-}$ as Surface Ligands. I. Am. Chem. Soc. 2011, 133, 10612-10620.

(15) Fafarman, A. T.; Koh, W.; Diroll, B. T.; Kim, D. K.; Ko, D.-K.; Oh, S. J.; Ye, X.; Doan-Nguyen, V.; Crump, M. R.; Reifsnyder, D. C.; et al. Thiocyanate-Capped Nanocrystal Colloids: Vibrational Reporter of Surface Chemistry and Solution-Based Route to Enhanced Coupling in Nanocrystal Solids. J. Am. Chem. Soc. 2011, 133, 15753-15761.

(16) Dirin, D. N.; Dreyfuss, S.; Bodnarchuk, M. I.; Nedelcu, G.; Papagiorgis, P.; Itskos, G.; Kovalenko, M. V. Lead Halide Perovskites and Other Metal Halide Complexes as Inorganic Capping Ligands for Colloidal Nanocrystals. I. Am. Chem. Soc. 2014, 136, 6550-6553.

(17) Zhang, H.; Jang, J.; Liu, W.; Talapin, D. V. Colloidal Nanocrystals with Inorganic Halide, Pseudohalide, and Halometallate Ligands. ACS Nano 2014, 8, 7359-7369.

(18) Kim, S.; Noh, J.; Choi, H.; Ha, H.; Song, J. H.; Shim, H. C.; Jang, J.; Beard, M. C.; Jeong, S. One-Step Deposition of Photovoltaic Layers Using Iodide Terminated PbS Quantum Dots. J. Phys. Chem. Lett. 2014, 5, 4002-4007.

(19) Bae, W. K.; Joo, J.; Padilha, L. a; Won, J.; Lee, D. C.; Lin, Q.; Koh, W.; Luo, H.; Klimov, V. I.; Pietryga, J. M. Highly Effective Surface Passivation of $\mathrm{PbSe}$ Quantum Dots through Reaction with Molecular Chlorine. I. Am. Chem. Soc. 2012, 134, 20160-20168.

(20) Woo, J. Y.; Ko, J.; Song, J. H.; Kim, K.; Choi, H.; Kim, Y.; Lee, D. C.; Jeong, S. Ultrastable PbSe Nanocrystal Quantum Dots via in Situ Formation of Atomically Thin Halide Adlayers on $\mathrm{PbSe}(100)$. J. Am. Chem. Soc. 2014, 136, 8883-8886.

(21) Law, M.; Luther, J. M.; Song, Q.; Hughes, B. K.; Perkins, C. L.; Nozik, A. J. Structural, Optical, and Electrical Properties of PbSe Nanocrystal Solids Treated Thermally or with Simple Amines. J. Am. Chem. Soc. 2008, 130, 5974-5985.

(22) Luther, J. M.; Law, M.; Song, Q.; Perkins, C. L.; Beard, M. C.; Nozik, A. J. Structural, Optical, and Electrical Properties of SelfAssembled Films of PbSe Nanocrystals Treated with 1,2-Ethanedithiol. ACS Nano 2008, 2, 271-280.

(23) Liu, Y.; Gibbs, M.; Puthussery, J.; Gaik, S.; Ihly, R.; Hillhouse, H. W.; Law, M. Dependence of Carrier Mobility on Nanocrystal Size and Ligand Length in PbSe Nanocrystal Solids. Nano Lett. 2010, 10, 1960-1969.

(24) Scheele, M.; Hanifi, D.; Zherebetskyy, D.; Chourou, S. T.; Axnanda, S.; Rancatore, B. J.; Thorkelsson, K.; Xu, T.; Liu, Z.; Wang, L.; et al. PbS Nanoparticles Capped with Tetrathiafulvalenetetracarboxylate: Utilizing Energy Level Alignment for Efficient Carrier Transport. ACS Nano 2014, 8, 2532-2540.

(25) Zhang, H.; Hu, B.; Sun, L.; Hovden, R.; Wise, F. W.; Muller, D. a; Robinson, R. D. Surfactant Ligand Removal and Rational Fabrication of Inorganically Connected Quantum Dots. Nano Lett. 2011, 11, 5356-5361.

(26) Liu, Y.; Tolentino, J.; Gibbs, M.; Ihly, R.; Perkins, C. L.; Liu, Y.; Crawford, N.; Hemminger, J. C.; Law, M. PbSe Quantum Dot FieldEffect Transistors with Air-Stable Electron Mobilities above $7 \mathrm{~cm}^{2} \mathrm{~V}^{-1}$ $\mathrm{S}^{-1}$. Nano Lett. 2013, 13, 1578-1587.

(27) Oh, S. J.; Berry, N. E.; Choi, J.-H.; Gaulding, E. A.; Lin, H.; Paik, T.; Diroll, B. T.; Muramoto, S.; Murray, C. B.; Kagan, C. R. Designing High-Performance $\mathrm{PbS}$ and $\mathrm{PbSe}$ Nanocrystal Electronic Devices through Stepwise, Post-Synthesis, Colloidal Atomic Layer Deposition. Nano Lett. 2014, 14, 1559-1566.

(28) Scheele, M.; Engel, J. H.; Ferry, V. E.; Hanifi, D.; Liu, Y.; Alivisatos, A. P. Nonmonotonic Size Dependence in the Hole Mobility of Methoxide-Stabilized PbSe Quantum Dot Solids. ACS Nano 2013, 7, 6774-6781.

(29) Tang, J.; Kemp, K. W.; Hoogland, S.; Jeong, K. S.; Liu, H.; Levina, L.; Furukawa, M.; Wang, X.; Debnath, R.; Cha, D.; et al. Colloidal-Quantum-Dot Photovoltaics Using Atomic-Ligand Passivation. Nat. Mater. 2011, 10, 765-771.

(30) Ning, Z.; Voznyy, O.; Pan, J.; Hoogland, S.; Adinolfi, V.; Xu, J.; Li, M.; Kirmani, A. R.; Sun, J.; Minor, J.; et al. Air-Stable N-Type Colloidal Quantum Dot Solids. Nat. Mater. 2014, 13, 822-828.

(31) Nagel, M.; Hickey, S. G.; Frömsdorf, A.; Kornowski, A.; Weller, H. Synthesis of Monodisperse PbS Nanoparticles and Their Assembly into Highly Ordered 3D Colloidal Crystals. Z. Phys. Chem. 2007, 221, 427-437.

(32) Houtepen, A. J.; Koole, R.; Vanmaekelbergh, D.; Meeldijk, J.; Hickey, S. G. The Hidden Role of Acetate in the PbSe Nanocrystal Synthesis. I. Am. Chem. Soc. 2006, 128, 6792-6793.

(33) Mokari, T.; Zhang, M.; Yang, P.; Shape. Size, and Assembly Control of PbTe Nanocrystals. I. Am. Chem. Soc. 2007, 129, 98649865.

(34) George, S. M. Atomic Layer Deposition: An Overview. Chem. Rev. 2010, 110, 111-131.

(35) Nag, A.; Chung, D. S.; Dolzhnikov, D. S.; Dimitrijevic, N. M.; Chattopadhyay, S.; Shibata, T.; Talapin, D. V. Effect of Metal Ions on Photoluminescence, Charge Transport, Magnetic and Catalytic Properties of All-Inorganic Colloidal Nanocrystals and Nanocrystal Solids. I. Am. Chem. Soc. 2012, 134, 13604-13615.

(36) Pourret, A.; Guyot-Sionnest, P.; Elam, J. W. Atomic Layer Deposition of $\mathrm{ZnO}$ in Quantum Dot Thin Films. Adv. Mater. 2009, 21, 232-235.

(37) Liu, Y.; Gibbs, M.; Perkins, C. L.; Tolentino, J.; Zarghami, M. H.; Bustamante, J.; Law, M. Robust, Functional Nanocrystal Solids by Infilling with Atomic Layer Deposition. Nano Lett. 2011, 11, 53495355.

(38) Zaumseil, J.; Sirringhaus, H. Electron and Ambipolar Transport in Organic Field-Effect Transistors. Chem. Rev. 2007, 107, 1296-1323.

(39) Dai, Q.; Wang, Y.; Li, X.; Zhang, Y.; Pellegrino, D. J.; Zhao, M.; Zou, B.; Seo, J.; Wang, Y.; Yu, W. W. Size-Dependent Composition and Molar Extinction Coefficient of PbSe Semiconductor Nanocrystals. ACS Nano 2009, 3, 1518-1524.

(40) Murray, C. B.; Norris, D. J.; Bawendi, M. G. Synthesis and Characterization of Nearly Monodisperse CdE (E = Sulfur, Selenium, Tellurium) Semiconductor Nanocrystallites. J. Am. Chem. Soc. 1993, $115,8706-8715$.

(41) Gaponik, N.; Talapin, D. V.; Rogach, A. L.; Eychmüller, A.; Weller, H. Efficient Phase Transfer of Luminescent Thiol-Capped Nanocrystals: From Water to Nonpolar Organic Solvents. Nano Lett. 2002, 2, 803-806.

(42) Pearson, R. G. Hard and Soft Acids and Bases. J. Am. Chem. Soc. 1963, 85, 3533-3539.

(43) Anderson, N. C.; Hendricks, M. P.; Choi, J. J.; Owen, J. S. Ligand Exchange and the Stoichiometry of Metal Chalcogenide Nanocrystals: Spectroscopic Observation of Facile Metal-Carboxylate Displacement and Binding. I. Am. Chem. Soc. 2013, 135, 1853618548.

(44) Bovey, L. F. H. The Infrared Absorption and Reflection Spectra of the Ammonium Halides. J. Opt. Soc. Am. 1951, 41, 836.

(45) Sykora, M.; Koposov, A. Y.; McGuire, J. A.; Schulze, R. K.; Tretiak, O.; Pietryga, J. M.; Klimov, V. I. Effect of Air Exposure on Surface Properties, Electronic Structure, and Carrier Relaxation in PbSe Nanocrystals. ACS Nano 2010, 4, 2021-2034.

(46) Zhang, J.; Song, T.; Zhang, Z.; Ding, K.; Huang, F.; Sun, B. Layered Ultrathin $\mathrm{PbI} 2$ Single Crystals for High Sensitivity Flexible Photodetectors. J. Mater. Chem. C 2015, 3, 4402-4406.

(47) Cho, K.-S.; Talapin, D. V.; Gaschler, W.; Murray, C. B. Designing PbSe Nanowires and Nanorings through Oriented Attachment of Nanoparticles. I. Am. Chem. Soc. 2005, 127, 7140-7147.

(48) Choi, H.; Ko, J.; Kim, Y.; Jeong, S. Steric-Hindrance-Driven Shape Transition in PbS Quantum Dots: Understanding SizeDependent Stability. J. Am. Chem. Soc. 2013, 135, 5278-5281. 
(49) Reichardt, C. Solvatochromic Dyes as Solvent Polarity Indicators. Chem. Rev. 1994, 94, 2319-2358.

(50) Leubner, S.; Hatami, S.; Esendemir, N.; Lorenz, T.; Joswig, J.O.; Lesnyak, V.; Recknagel, S.; Gaponik, N.; Resch-Genger, U.; Eychmüller, A. Experimental and Theoretical Investigations of the Ligand Structure of Water-Soluble CdTe Nanocrystals. Dalton Trans. 2013, 42, 12733-12740.

(51) Choi, J. H.; Fafarman, A. T.; Oh, S. J.; Ko, D. K.; Kim, D. K.; Diroll, B. T.; Muramoto, S.; Gillen, J. G.; Murray, C. B.; Kagan, C. R. Bandlike Transport in Strongly Coupled and Doped Quantum Dot Solids: A Route to High-Performance Thin-Film Electronics. Nano Lett. 2012, 12, 2631-2638.

(52) Zabet-Khosousi, A.; Dhirani, A.-A. Charge Transport in Nanoparticle Assemblies. Chem. Rev. 2008, 108, 4072-4124.

(53) Döllefeld, H.; Weller, H.; Eychmüller, A. Particle-Particle Interactions in Semiconductor Nanocrystal Assemblies. Nano Lett. 2001, 1, 267-269.

(54) Döllefeld, H.; Weller, H.; Eychmüller, A. Semiconductor Nanocrystal Assemblies: Experimental Pitfalls and a Simple Model of Particle-Particle Interaction. J. Phys. Chem. B 2002, 106, 56045608.

(55) Kagan, C. R.; Andry, P. Thin-Film Transistors, 1st ed.; MarcellDekker: New York, 2003.

(56) Jähnig, F.; Bozyigit, D.; Yarema, O.; Wood, V. Research Update: Comparison of Salt- and Molecular-Based Iodine Treatments of $\mathrm{PbS}$ Nanocrystal Solids for Solar Cells. APL Mater. 2015, 3, 020701.

(57) Ponce Ortiz, R.; Facchetti, A.; Marks, T. J. High-K Organic, Inorganic, and Hybrid Dielectrics for Low-Voltage Organic FieldEffect Transistors. Chem. Rev. 2010, 110, 205-239. 